\title{
Associations of C-Reactive Protein to Indices of Vascular Health and the Influence of Serum 25(OH)D Status in Healthy Adults
}

\author{
Ambika P. Ashraf, ${ }^{1}$ Gordon Fisher, ${ }^{2}$ Jessica Alvarez, ${ }^{2}$ Tanja Dudenbostel, ${ }^{3}$ \\ David A. Calhoun, ${ }^{3}$ Alexander J. Szalai, ${ }^{4}$ and Barbara A. Gower ${ }^{2}$ \\ ${ }^{1}$ Division of Pediatric Endocrinology and Metabolism, Department of Pediatrics, The Children's Hospital, \\ University of Alabama at Birmingham, Birmingham, AL 35233, USA \\ ${ }^{2}$ Department of Nutrition Sciences, University of Alabama at Birmingham, Birmingham, AL 35233, USA \\ ${ }^{3}$ Vascular Biology and Hypertension Program, University of Alabama at Birmingham, Birmingham, AL 35233, USA \\ ${ }^{4}$ Division of Clinical Immunology and Rheumatology, Department of Medicine, University of Alabama at Birmingham, \\ Birmingham, AL 35233, USA
}

Correspondence should be addressed to Ambika P. Ashraf, aashraf@peds.uab.edu

Received 21 June 2012; Accepted 22 August 2012

Academic Editor: Christel Lamberg-Allardt

Copyright (C) 2012 Ambika P. Ashraf et al. This is an open access article distributed under the Creative Commons Attribution License, which permits unrestricted use, distribution, and reproduction in any medium, provided the original work is properly cited.

\begin{abstract}
Elevated serum high-sensitivity C-reactive protein (hs-CRP) and low serum 25-hydroxyvitamin D [25(OH)D] are associated with increased cardiovascular disease (CVD) risk. Ethnic differences in serum hs-CRP and 25(OH)D concentrations and CVD are known. Objectives: to investigate the ethnic differences in hs-CRP concentrations, to assess the influence of 25(OH)D on these ethnic differences and to examine the influence of $25(\mathrm{OH}) \mathrm{D}$ on association between hs-CRP and cardiovascular health indices. Subjects: 62 healthy adults [26 African Americans (AA), 26 European Americans (EA), and 10 Hispanic Americans (HA)], ages 18-55 years. Serum hs-CRP and 25(OH)D as well as pulse wave velocity (PWV), augmentation index (AIx), and flow-mediated dilatation (FMD) were measured. hs-CRP was inversely associated with $25(\mathrm{OH}) \mathrm{D}(r=-0.25, P=0.049)$, and hs-CRP was positively associated with PWV $(r=0.29, P=0.04)$. The association of hs-CRP with PWV attenuated after adjustment for $25(\mathrm{OH}) \mathrm{D}(P=0.15)$. hs-CRP was higher in AA compared to EA $(P=0.05)$; this differences was reduced by $32 \%$ after adjusting for serum $25(\mathrm{OH}) \mathrm{D}$. Conclusion: eventhough the inverse association between serum $25(\mathrm{OH}) \mathrm{D}$ and CRP does not infer causality, lower serum 25(OH)D may increase risk for inflammation and endothelial dysfunction. The lower 25(OH)D in AA may predispose to greater inflammation and associated vascular dysfunction.
\end{abstract}

\section{Introduction}

Chronic inflammatory stress, endothelial dysfunction, and arterial stiffness are key underlying factors in the pathogenesis of atherosclerosis $[1,2]$. C-reactive protein (CRP), an acute phase protein synthesized primarily in the liver, is an established biomarker of inflammation, is known to alter endothelial function via increased nitric oxide production [3] and its serum levels are positively associated with the development of cardiovascular disease (CVD) [4-6]. Highsensitivity C-reactive protein (hs-CRP) concentration is also associated with pulse wave velocity (PWV), the gold standard for assessing arterial stiffness, suggesting that inflammation is linked to arterial stiffness [7-9].

There is evidence that African Americans (AA) and Hispanic Americans (HA) have a greater risk of complications from CVD compared with European Americans (EA) $[10,11]$. However to date, results vary as to whether or not inflammation differs between AA and EA. Khera et al. found higher hs-CRP concentrations among AA men and women between ages 30-65 years as compared to EA [12], whereas we have previously shown no differences in hs-CRP concentrations between AA and EA premenopausal women [13]. Additionally, AA have been shown to have greater 
arterial stiffness and endothelial dysfunction compared to EA [14-16]. Endothelial dysfunction and arterial stiffness are early and integral components of atherosclerosis and are novel biomarkers of CVD $[17,18]$. Given the current magnitude of ethnic health disparities, it is paramount to identify and recognize race and ethnicity-related differences in cardiovascular risk factors.

Vitamin D is hypothesized to have anti-inflammatory and cardioprotective properties and can potentially regulate proinflammatory cytokines $[19,20]$. Serum concentration of 25-hydroxyvitamin D [25(OH)D], the indicator of vitamin $\mathrm{D}$ status, is associated with serum hs-CRP concentrations [21]. Several researchers have demonstrated a potential link between vitamin $\mathrm{D}$ status and noninvasive indices of arterial stiffness and brachial artery distensibility measured by flowmediated dilatation (FMD) [22-24]. As AA are likely to have vitamin $\mathrm{D}$ deficiency [25], ethnic differences in vitamin $\mathrm{D}$ status may partially account for the ethnic differences in inflammatory biomarkers and vascular function. Although studies have examined the associations between hs-CRP, vascular resistance, and endothelial function indices [26, 27], the influence of $25(\mathrm{OH}) \mathrm{D}$ status on these outcomes is yet to be determined.

The primary objective of this study was to test the hypothesis that observed higher CRP in AA is due in part to their lower circulating vitamin D. A secondary objective was to determine whether vitamin D status influenced the associations between hs-CRP and cardiovascular risk markers (heart rate, brachial artery blood pressure (BP), central aortic BP, MAP, aortic PP, pulse wave velocity (PWV), augmentation index (AIx), and flow mediated dilatation $($ FMD $))$ in healthy nonobese adults.

\section{Materials and Methods}

Subjects were 62 adults, both sexes, age $18-55$ years who were previously enrolled in 2 observational cohort studies: the VIVID study and the DIVA study (clinical trial registration numbers: NCT01041547, NCT01041365). The Institutional Review Board of the University of Alabama at Birmingham (UAB) approved both studies, and written informed consent was obtained before entry to the study. Ethnicity (European American-EA, African American-AA, or Hispanic American-HA) was self-reported. Exclusion criteria were diabetes, hypertension, or other conditions known to influence insulin sensitivity or vascular function; antihypertensive, glucose-controlling, or lipid-lowering medications, or other medications known to modify vascular function; vitamin D supplementation, smoking; BMI $>322 \mathrm{~kg} / \mathrm{m}^{2}$, or lactose intolerance.

Testing was performed on 2 separate days in the same week. Blood samples, seated and supine systolic and diastolic blood pressure (SBP and DBP), and anthropometrics were obtained in the UAB Clinical Research Unit of the Center of Clinical and Translation Science (CCTS) and the Department of Nutrition Sciences after a $12 \mathrm{hr}$ fast. Body composition (fat and lean mass) was assessed using dual-energy X-ray absorptiometry (iDXA, GE-LUNAR Radiation Corp., Madison, WI).
During a second morning visit after an $8 \mathrm{hr}$ fast, radial pulse wave analysis (PWA), carotid-femoral PWV, and FMD testing were conducted by a single physician in the Diabetes Research Training Center (DRTC) Human Physiology Core Cardiodynamic Laboratory. Brachial artery distensibility (FMD) was measured by brachial ultrasound imaging with a $7.5 \mathrm{MHz}$ linear-array probe (Philips HP Agilent Sonos 5500, Andover, MA) according to standard guidelines [28]. Radial PWA and carotid-femoral PWV were performed using SphygmoCor applanation tonometry system (AtCor Medical, Sydney, Australia) as previously described [29]. Radial PWA was performed for assessment of augmentation index (AIx), AIx adjusted to a heart rate of 75 beat $/ \mathrm{min}$ (AIx75), central aortic systolic blood pressure (aSBP) and central aortic diastolic blood pressure (aDBP).

All analyses were conducted in the Core Laboratory of the University of Alabama at Birmingham DRTC. hs-CRP was assayed with the Stanbio Sirrus using a turbidimetric procedure. Mean sensitivity is $0.50 \mathrm{mg} / \mathrm{L}$ and interassay $\mathrm{CV}$ is $8.9 \%$. Serum $25(\mathrm{OH}) \mathrm{D}$ concentrations were assayed with a liquid chromatography-tandem mass spectrometry technique (Quest Diagnostics Nichols Institute, San Juan Capistrano, CA).

2.1. Statistical Analyses. Descriptive characteristics are reported as means $( \pm$ SDs). The distributions of all variables were examined, and variables that deviated from a normal distribution were $\log 10$-transformed prior to statistical analyses. Between-race differences for each variable were determined using a one-way ANOVA. Bonferroni post hoc analyses were performed when statistically significant differences were observed. In order to further explore factors that contributed to observed differences between race, a univariate analysis was performed on variables that were statistically significant, using \%fat, $25(\mathrm{OH}) \mathrm{D}$, as covariates in the analyses. Hispanic subjects were not included in the race analysis due to their smaller number. To determine if subjects differed based on their vitamin $\mathrm{D}$ status, subjects were divided based on serum $25(\mathrm{OH}) \mathrm{D} \geq 20 \mathrm{ng} / \mathrm{mL}$ and $<20 \mathrm{ng} / \mathrm{mL}[30,31]$. Group differences according to serum $25(\mathrm{OH}) \mathrm{D}$ status for each variable were determined with 2-group $t$-tests. Pearson correlation analyses were used to investigate the relationships between hs-CRP, serum $25(\mathrm{OH}) \mathrm{D}$, and vascular measures. Serum $25(\mathrm{OH}) \mathrm{D}$ and percent body fat were further examined as potential confounders in MLR analyses to investigate the relationships between hs-CRP and vascular outcomes. All analyses were performed using the statistical package for the social sciences (SPSS, version 19.0, Chicago, IL).

\section{Results}

A total of 62 subjects (26 EA, 26 AA, $10 \mathrm{HA}$ ) were included. Hispanic subjects were not included in the ethnic-specific analysis due to their limited number. AA had lower 25(OH)D $(P=0.001)$ and higher BMI $(P=0.03)$, percent body fat $(P=0.02), \operatorname{AIx75}(P=0.001), \operatorname{PWV}(P=0.002)$, and CRP $(P=0.05)$ compared to EA-see Table 1 . When 
TABLE 1: Descriptive statistics and outcome variables by race in young adults.

\begin{tabular}{|c|c|c|c|c|}
\hline Variable & $\begin{array}{c}\text { EA } \\
(N=26)\end{array}$ & $\begin{array}{c}\text { AA } \\
(N=26)\end{array}$ & $\begin{array}{c}\text { HA } \\
(N=10)\end{array}$ & $\begin{array}{l}P \text { value } \\
\quad * P\end{array}$ \\
\hline Age (years) & $28 \pm 9.9$ & $32 \pm 10.5$ & $28 \pm 5.9$ & $P=0.36$ \\
\hline Females \% & $76.9 \%$ & $84.6 \%$ & $40 \%$ & $P=\mathbf{0 . 0 2}$ \\
\hline BMI $\left(\mathrm{kg} / \mathrm{m}^{2}\right)$ & $23.3 \pm 3.1$ & $25.6 \pm 4$ & $25.5 \pm 3.7$ & $\begin{aligned} P & =0.06 \\
* & =\mathbf{0 . 0 3}^{\mathrm{a}}\end{aligned}$ \\
\hline Waist circumference $(\mathrm{cm})$ & $74.7 \pm 9.2$ & $78.9 \pm 10.6$ & $83.9 \pm 11$ & $P=\mathbf{0 . 0 5}$ \\
\hline Percent body fat (\%) & $29.1 \pm 6.9$ & $34.2 \pm 8.3$ & $31.8 \pm 8.5$ & $\begin{aligned} P & =0.06 \\
* P & =\mathbf{0 . 0 2}^{\mathrm{b}}\end{aligned}$ \\
\hline $25(\mathrm{OH}) \mathrm{D}(\mathrm{ng} / \mathrm{mL})$ & $28.6 \pm 8.8$ & $15.3 \pm 5.5$ & $24.2 \pm 5.3$ & $\begin{array}{c}P=\mathbf{0 . 0 0 1} \\
* P=\mathbf{0 . 0 0 1}^{\mathrm{c}}\end{array}$ \\
\hline hs-CRP (mg/L) & $1.01 \pm 0.73$ & $2.3 \pm 3.2$ & $1.04 \pm 0.58$ & $\begin{aligned} P & =0.09 \\
{ }^{*} P & =\mathbf{0 . 0 5}^{\mathrm{d}}\end{aligned}$ \\
\hline Heart rate (beats/min) & $64.9 \pm 9.2$ & $70.1 \pm 12.3$ & $68.4 \pm 7.3$ & $P=0.20$ \\
\hline Brachial SBP (mm Hg) & $112.3 \pm 13.8$ & $111.2 \pm 14.3$ & $113.8 \pm 11.2$ & $P=0.88$ \\
\hline Brachial DBP (mm Hg) & $68.4 \pm 7.9$ & $68.8 \pm 9.1$ & $71.3 \pm 12.5$ & $P=0.7$ \\
\hline Aortic SBP (mm Hg) & $99.6 \pm 9.6$ & $102.9 \pm 6.9$ & $102.9 \pm 11.8$ & $P=0.35$ \\
\hline Aortic DBP (mm Hg) & $70.4 \pm 9.4$ & $73.7 \pm 6.7$ & $77.1 \pm 8.5$ & $P=0.090$ \\
\hline MAP (mm Hg) & $82.4 \pm 8.7$ & $83.7 \pm 10.1$ & $85.3 \pm 10.5$ & $P=0.71$ \\
\hline Aortic PP & $29.2 \pm 6.7$ & $29.3 \pm 4.7$ & $25.8 \pm 4.9$ & $P=0.25$ \\
\hline FMD $(\%)$ & $10.6 \pm 3.9$ & $8.8 \pm 2.8$ & $7.8 \pm 2.2$ & $\begin{array}{c}P=\mathbf{0 . 0 4} \\
* P=\mathbf{0 . 0 7}\end{array}$ \\
\hline Aix at $75(\%)$ & $0.74 \pm 12.1$ & $10.9 \pm 8.6$ & $2.2 \pm 12.3$ & $\begin{aligned} P & =\mathbf{0 . 0 0 5} \\
* P & =0.001^{\mathrm{e}}\end{aligned}$ \\
\hline $\mathrm{PWV}(\mathrm{m} / \mathrm{s})$ & $6.2 \pm 0.7$ & $7.1 \pm 1.1$ & $6.5 \pm 0.70$ & $\begin{array}{c}P=\mathbf{0 . 0 0 6} \\
{ }^{*} P=\mathbf{0 . 0 0 2}^{\mathrm{f}}\end{array}$ \\
\hline
\end{tabular}

** Bold face values denote significance $P<0.05 . P$ = between 3 races.

${ }^{*} P^{\mathrm{a}, \mathrm{b}, \mathrm{c}, \mathrm{d}, \mathrm{e}, \mathrm{f}}=$ super scripts are significant $P$ values showing differences between AA and EA for post hoc analysis. Continuous variables are expressed as mean $\pm \mathrm{SD}$, categorical variables are expressed as percentage.

Abbreviations: MAP: mean arterial pressure; Aortic PP: aortic pulse pressure; AIx75: augmentation index standardized to a heart rate of 75 beats/min; PWV: pulse wave velocity; FMD: flow-mediated dilation; SBP: systolic blood pressure; DBP: diastolic blood pressure.

EA and AA subjects combined, hs-CRP was inversely associated with $25(\mathrm{OH}) \mathrm{D}(r=-0.25, P=0.049)$-see Figure 1. The association of hs-CRP with $25(\mathrm{OH}) \mathrm{D}$ persisted after adjusting for age, sex, and percent body fat, but was attenuated after adjusting for race $(P=0.069)$ see Figure 1. After adjustment for $25(\mathrm{OH}) \mathrm{D}$, the ethnic difference in CRP was reduced by $32 \%(P=0.13)$ - see Figure 2. In subanalysis, hs-CRP was inversely associated with $25(\mathrm{OH}) \mathrm{D}$ in EA $(r=-0.54, P=0.004)$, and this persisted even after adjustment of age, sex, and percent body fat $(r=-0.58, P=0.002)$. hs-CRP was not associated with vitamin D status in AA. Due to the small sample size, we could not conduct analyses within the HA group.

Serum 25(OH)D was associated with PWV after adjusting for race $(r=-0.303 ; P=0.034)$. hs-CRP was positively associated with PWV $(r=0.29, P=0.04)$ and heart rate $(r=0.295, P=0.02)$, but not with brachial or aortic SBP/ DBP, mean arterial pressure (MAP), aortic pulse pressure (PP), AIx75, or FMD. The association of hs-CRP with PWV attenuated after adjustment for BMI $(r=0.24, P=0.09)$ and disappeared after adjustment for 25(OH)D concentrations $(r=0.20, P=0.15)$ and after adjustment for race $(r=0.261$;
$P=0.07)$. The association with heart rate persisted after adjustment for percent fat and 25(OH)D.

When classified based on serum $25(\mathrm{OH}) \mathrm{D}$ concentrations $(<20 \mathrm{ng} / \mathrm{mL}$ and $>20 \mathrm{ng} / \mathrm{mL}), 27$ subjects $(43.5 \%)$ had serum $25(\mathrm{OH}) \mathrm{D}<20 \mathrm{ng} / \mathrm{mL}$. Subjects with $<20 \mathrm{ng} / \mathrm{mL}$ $25(\mathrm{OH}) \mathrm{D}$ had higher body weight $(P=0.002)$, BMI $(P=$ $0.03)$, hs-CRP $(P=0.001)$, AIx75 $(P=0.001)$, and PWV $(P=0.015)$ as compared to individuals with serum $25(\mathrm{OH}) \mathrm{D}>20 \mathrm{ng} / \mathrm{mL}$, when adjusting for age, race, \%fat, and gender.

\section{Discussion}

In the present study, we have shown that hs-CRP is higher in $\mathrm{AA}$, and this ethnic difference is attenuated by adjustment for vitamin D status. Moreover, hs-CRP is positively associated with PWV (a measure of arterial stiffness) and vitamin D may influence this association. These observations suggest that relatively low circulating concentrations of $25(\mathrm{OH}) \mathrm{D}$ may increase risk for inflammation and endothelial dysfunction, even in healthy young adults. 


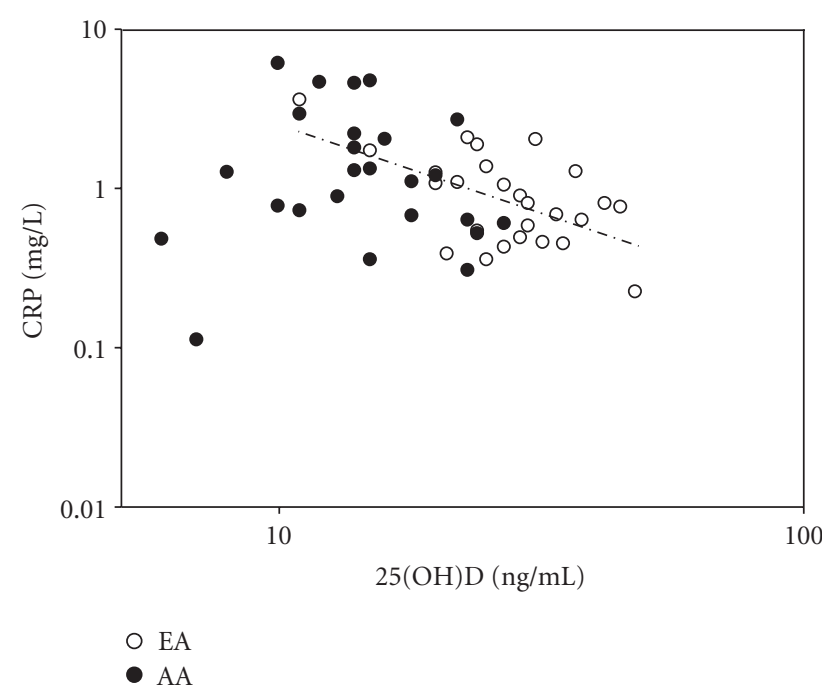

Figure 1: Associations of serum hs-CRP with 25(OH)D. hs-CRP was inversely associated with $25(\mathrm{OH}) \mathrm{D}(r=-0.25, P=0.049)$ as a group. In EA $r=-0.544, P=0.004$ and in AA, there was no relationship $r=0.015, P=0.94$.

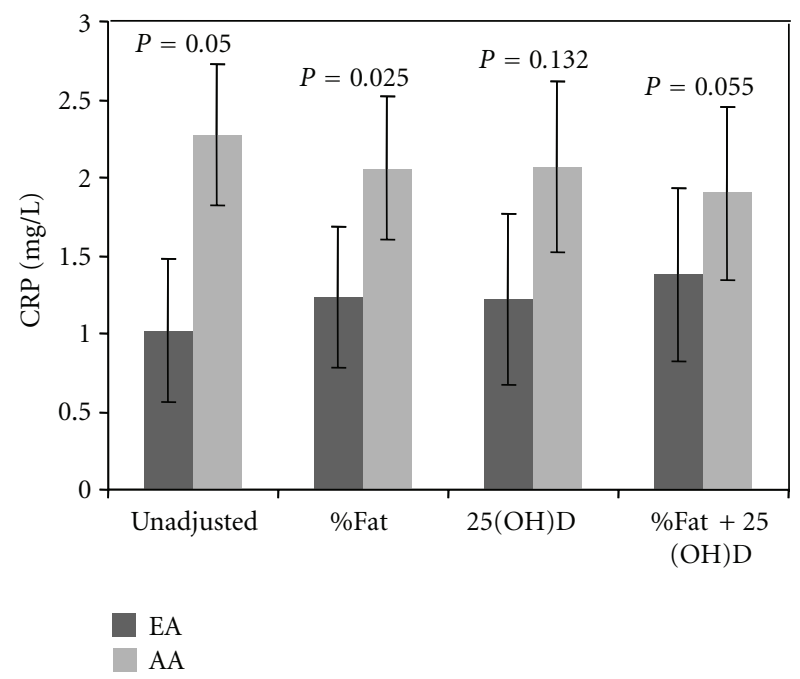

Figure 2: Ethnic differences in hs-CRP (a) unadjusted, (b) adjusted for percent body fat, (c) adjusted for $25(\mathrm{OH}) \mathrm{D}$, and (d) further adjusted for percent body fat and $25(\mathrm{OH}) \mathrm{D}$. After adjusting for serum concentration of $25(\mathrm{OH}) \mathrm{D}$, there was a $32 \%$ reduction in hs-CRP difference between AA and EA.

Serum hs-CRP is an independent risk factor for development of hypertension, endothelial dysfunction, arterial stiffness, and atherosclerosis $[5,32,33]$. We confirmed that AA have poorer vascular function indices, lower $25(\mathrm{OH}) \mathrm{D}$ concentrations, and higher hs-CRP, as shown in other studies $[16,34]$. AA subjects also reportedly have a greater prevalence of coronary heart disease and mortality rates [35]. Although ethnic differences in vascular function are well known, the pathophysiological basis for these differences remains elusive. It is conceivable that vitamin D deficiency may trigger acute phase-reactant production, equivalent to a low-grade systemic inflammation. After adjustment for percent fat and serum $25(\mathrm{OH}) \mathrm{D}$, the difference in hs-CRP between AA and EA was diminished, which may have relevant clinical implications and partially explain these ethnic differences.

In our cohort, hs-CRP was associated with serum $25(\mathrm{OH}) \mathrm{D}$ which is consistent with previous reports [36]. Nevertheless, in our data, serum $25(\mathrm{OH}) \mathrm{D}$ was strongly associated with hs-CRP only in EA and the association persisted even after adjusting for BMI and percent fat. One explanation for the absence of an association of $25(\mathrm{OH}) \mathrm{D}$ and hs-CRP in AA could be masked by their almost ubiquitous vitamin $\mathrm{D}$ deficiency. As most of the AA subjects had a $25(\mathrm{OH}) \mathrm{D}<20 \mathrm{ng} / \mathrm{mL}$, a large number of subjects may be required to detect an association. In our sample, the EA were predominantly responsible for the observed relationship between hs-CRP and 25(OH)D. With a larger sample size of AA subject, a possible association may manifest. A noteworthy observation by Amer and Qayyum [36] in a large cohort of asymptomatic adults shows that there was reduction in CRP for each $10 \mathrm{ng} / \mathrm{mL}$ increase in serum $25(\mathrm{OH}) \mathrm{D}$ as long as serum $25(\mathrm{OH}) \mathrm{D}$ was $\leq 21 \mathrm{ng} / \mathrm{mL}$, and CRP started increasing with increasing $25(\mathrm{OH}) \mathrm{D}$ concentrations above $>21 \mathrm{ng} / \mathrm{mL}$. They have not reported ethnic-specific cutoffs for this finding. Although the implications of these observations are not clear, there could be different threshold levels in AA and EA above which raising the $25(\mathrm{OH}) \mathrm{D}$ concentrations may not be helpful in improving the hs-CRP.

In this study, we observed an association between CRP and PWV. It has been reported that PWV is an independent predictor of cardiovascular events [37]. We found that adjustment for serum $25(\mathrm{OH}) \mathrm{D}$, attenuated the association between hs-CRP and PWV, suggesting that vitamin D status influences this relationship. Several reports have previously alluded to the fact that vitamin $\mathrm{D}$ can serve as an anti-inflammatory agent. Vitamin D3 supplementation was found to reduce the proinflammatory cytokine tumor necrosis factor $\alpha$ and enhance the anti-inflammatory interleukin 10 , in a cohort of subjects with congestive heart failure. However, their CRP did not change [38]. Because of the inflammatory component of atherosclerosis and because elevated hs-CRP is reportedly associated with cardiovascular disease, it is critical to understand the factors responsible for elevated hs-CRP. Vitamin D supplementation may be an additive therapeutic option for conditions accompanied by increased inflammation and a subsequent decline in cardiovascular health.

Limitations of the study are cross-sectional nature and relatively smaller sample size which limits our ability to conclude causality based on observational associations. Controlled clinical trials are required to clarify whether vitamin D supplementation reduces ethnicity differences in hs-CRP and whether vitamin D supplementation influences the associations between hs-CRP and vascular health indices.

Strengths of the study are inclusion of subjects with body mass index $<32 \mathrm{~kg} / \mathrm{m}^{2}$, inclusion of DXA measure of body fat, and inclusion of young healthy adults-a population where preventive interventions could have a 
profound impact on health. Moreover, we were able to utilize direct accurate measures of arterial stiffness, endothelial function, and central BP parameters.

We conclude that ethnic differences in hs-CRP may be mediated by unequal vitamin D status. Likewise, hs-CRP is higher in subjects with vitamin D deficiency. Furthermore, serum 25(OH)D influences the association between hs-CRP and PWV, a direct measure of arterial stiffness.

\section{Authors' Contribution}

Both A. P. Ashraf and G. Fisher contributed equally to this paper.

\section{Conflict of Interests}

The authors declare that they have no conflict of interests.

\section{Acknowledgments}

This study was funded by the UAB Diabetes Research Training Center (P60 DK- 079626), the Center for Clinical and Translational Science (5UL1 RR025777), the NORC (P30 DK56336), and Child Health Research Center Grant K12 HD043397 (T0909180013). G. Fisher is supported by the NIH T-32 Grant (T32DK062710), and J. A. Alvarez was supported by the American Heart Association (Greater Southeast Affiliate). Clinical Trial Registration no. NCT01041547, NCT01041365.

\section{References}

[1] R. A. Stancliffe, T. Thorpe, and M. B. Zemel, "Dairy attentuates oxidative and inflammatory stress in metabolic syndrome," American Journal of Clinical Nutrition, vol. 94, no. 2, pp. 422-430, 2011.

[2] C. Zhang, "The role of inflammatory cytokines in endothelial dysfunction," Basic Research in Cardiology, vol. 103, no. 5, pp. 398-406, 2008.

[3] B. R. Clapp, G. M. Hirschfield, C. Storry et al., "Inflammation and endothelial function: direct vascular effects of human Creactive protein on nitric oxide bioavailability," Circulation, vol. 111, no. 12, pp. 1530-1536, 2005.

[4] P. M. Ridker, C. H. Hennekens, J. E. Buring, and N. Rifai, "C-reactive protein and other markers of inflammation in the prediction of cardiovascular disease in women," New England Journal of Medicine, vol. 342, no. 12, pp. 836-843, 2000.

[5] P. M. Ridker and N. Cook, "Clinical usefulness of very high and very low levels of C-reactive protein across the full range of framingham risk scores," Circulation, vol. 109, no. 16, pp. 1955-1959, 2004.

[6] A. Ray, M. V. Huisman, J. T. Tamsma et al., "The role of inflammation on atherosclerosis, intermediate and clinical cardiovascular endpoints in type 2 diabetes mellitus," European Journal of Internal Medicine, vol. 20, no. 3, pp. 253-260, 2009.

[7] G. Mancia, G. De Backer, A. Dominiczak et al., "2007 guidelines for the management of arterial hypertension: the task force for the management of arterial hypertension of the European Society of Hypertension (ESH) and of the European
Society of Cardiology (ESC)," Journal of Hypertension, vol. 25, no. 6, pp. 1105-1187, 2007.

[8] M. Nagano, M. Nakamura, K. Sato, F. Tanaka, T. Segawa, and K. Hiramori, "Association between serum C-reactive protein levels and pulse wave velocity: a population-based crosssectional study in a general population," Atherosclerosis, vol. 180, no. 1, pp. 189-195, 2005.

[9] J. S. Kim, T. S. Kang, J. B. Kim et al., "Significant association of C-reactive protein with arterial stiffness in treated nondiabetic hypertensive patients," Atherosclerosis, vol. 192, no. 2, pp. 401-406, 2007.

[10] E. Saunders and E. Ofili, "Epidemiology of atherothrombotic disease and the effectiveness and risks of antiplatelet therapy: race and ethnicity considerations," Cardiology in Review, vol. 16, no. 2, pp. 82-88, 2008.

[11] D. Lloyd-Jones, R. J. Adams, T. M. Brown et al., "Heart disease and stroke statistics-2010 update: a report from the american heart association," Circulation, vol. 121, no. 7, pp. e46-e215, 2010.

[12] A. Khera, D. K. McGuire, S. A. Murphy et al., "Race and gender differences in C-reactive protein levels," Journal of the American College of Cardiology, vol. 46, no. 3, pp. 464-469, 2005.

[13] G. Fisher, T. C. Hyatt, G. R. Hunter, R. A. Oster, R. A. Desmond, and B. A. Gower, "Markers of inflammation and fat distribution following weight loss in African-American and white women," Obesity, vol. 20, pp. 715-720, 2011.

[14] V. L. Roger, A. S. Go, D. M. Lloyd-Jones et al., "Heart disease and stroke statistics-2011 update: a report from the American Heart Association," Circulation, vol. 123, no. 4, pp. e18-e19, 2011.

[15] U. Campia, W. K. Choucair, M. B. Bryant, M. A. Waclawiw, C. Cardillo, and J. A. Panza, "Reduced endothelium-dependent and -independent dilation of conductance arteries in African Americans," Journal of the American College of Cardiology, vol. 40, no. 4, pp. 754-760, 2002.

[16] K. S. Heffernan, S. Y. Jae, K. R. Wilund, J. A. Woods, and B. Fernhall, "Racial differences in central blood pressure and vascular function in young men," American Journal of Physiology, vol. 295, no. 6, pp. H2380-H2387, 2008.

[17] D. Liao, D. K. Arnett, H. A. Tyroler et al., "Arterial stiffness and the development of hypertension: the ARIC study," Hypertension, vol. 34, no. 2, pp. 201-206, 1999.

[18] S. P. Glasser and T. Dudenbostel, "The global burden of cardiovascular disease: the role of endothelial function and arterial elasticity in cardiovascular disease as novel and emerging biomarkers," Current Cardiovascular Risk Reports, vol. 5, pp. 187-195, 2011.

[19] X. Guillot, L. Semerano, N. Saidenberg-Kermanac'h, G. Falgarone, and M. C. Boissier, "Vitamin D and inflammation," Joint Bone Spine, vol. 77, no. 6, pp. 552-557, 2010.

[20] A. V. Krishnan and D. Feldman, "Mechanisms of the anticancer and anti-inflammatory actions of vitamin D," Annual Review of Pharmacology and Toxicology, vol. 51, pp. 311-336, 2011.

[21] M. T. E. Puts, M. Visser, J. W. R. Twisk, D. J. H. Deeg, and P. Lips, "Endocrine and inflammatory markers as predictors of frailty," Clinical Endocrinology, vol. 63, no. 4, pp. 403-411, 2005.

[22] G. M. London, A. P. Guérin, F. H. Verbeke et al., "Mineral metabolism and arterial functions in end-stage renal disease: potential role of 25-hydroxyvitamin D deficiency," Journal of 
the American Society of Nephrology, vol. 18, no. 2, pp. 613-620, 2007.

[23] L. A. J. L. M. Braam, A. P. G. Hoeks, F. Brouns, K. Halmuyák, M. J. W. Gerichhausen, and C. Vermeer, "Beneficial effects of vitamins $\mathrm{D}$ and $\mathrm{K}$ on the elastic properties of the vessel wall in postmenopausal women: a follow-up study," Thrombosis and Haemostasis, vol. 91, no. 2, pp. 373-380, 2004.

[24] J. A. Sugden, J. I. Davies, M. D. Witham, A. D. Morris, and A. D. Struthers, "Vitamin D improves endothelial function in patients with Type 2 diabetes mellitus and low vitamin D levels," Diabetic Medicine, vol. 25, no. 3, pp. 320-325, 2008.

[25] E. A. Yetley, "Assessing the vitamin D status of the US population," American Journal of Clinical Nutrition, vol. 88, no. 2, pp. 558S-564S, 2008.

[26] W. Schumacher, J. Cockcroft, N. J. Timpson et al., "Association between C-reactive protein genotype, circulating levels, and aortic pulse wave velocity," Hypertension, vol. 53, no. 2, pp. 150-157, 2009.

[27] Yasmin, C. M. McEniery, S. Wallace, I. S. Mackenzie, J. R. Cockcroft, and I. B. Wilkinson, "C-reactive protein is associated with arterial stiffness in apparently healthy individuals," Arteriosclerosis, Thrombosis, and Vascular Biology, vol. 24, no. 5, pp. 969-974, 2004.

[28] M. C. Corretti, T. J. Anderson, E. J. Benjamin et al., "Guidelines for the ultrasound assessment of endothelial-dependent flow-mediated vasodilation of the brachial artery: a report of the international brachial artery reactivity task force," Journal of the American College of Cardiology, vol. 39, no. 2, pp. 257265, 2002.

[29] E. Pimenta, K. K. Gaddam, S. Oparil et al., "Effects of dietary sodium reduction on blood pressure in subjects with resistant hypertension: results from a randomized trial," Hypertension, vol. 54, no. 3, pp. 475-481, 2009.

[30] Institute of Medicine, Dietary Reference Intakes for Calcium and Vitamin D, National Academies Press, Washington, DC, USA, 2011.

[31] M. F. Holick, "Vitamin D deficiency," New England Journal of Medicine, vol. 357, no. 3, pp. 266-281, 2007.

[32] K. Kusche-Vihrog, K. Urbanova, A. Blanqué et al., "Creactive protein makes human endothelium stiff and tight," Hypertension, vol. 57, no. 2, pp. 231-237, 2011.

[33] T. W. Hein, U. Singh, J. Vasquez-Vivar, S. Devaraj, L. Kuo, and I. Jialal, "Human C-reactive protein induces endothelial dysfunction and uncoupling of eNOS in vivo," Atherosclerosis, vol. 206, no. 1, pp. 61-68, 2009.

[34] S. E. Kasim-Karakas, "Ethnic differences in the insulin resistance syndrome," American Journal of Clinical Nutrition, vol. 71, no. 3, pp. 670-671, 2000.

[35] M. A. Albert and P. M. Ridker, "Inflammatory biomarkers in African Americans: a potential link to accelerated atherosclerosis," Reviews in Cardiovascular Medicine, vol. 5, no. 3, supplement, pp. S22-S27, 2004.

[36] M. Amer and R. Qayyum, "Relation between serum 25hydroxyvitamin D and C-reactive protein in asymptomatic adults (from the continuous national health and nutrition examination survey 2001 to 2006)," American Journal of Cardiology, vol. 109, pp. 226-230, 2012.

[37] C. Vlachopoulos, K. Aznaouridis, and C. Stefanadis, "Prediction of cardiovascular events and all-cause mortality with arterial stiffness: a systematic review and meta-analysis," Journal of the American College of Cardiology, vol. 55, no. 13, pp. 1318-1327, 2010.
[38] S. S. Schleithoff, A. Zittermann, G. Tenderich, H. K. Berthold, P. Stehle, and R. Koerfer, "Vitamin D supplementation improves cytokine profiles in patients with congestive heart failure: a double-blind, randomized, placebo-controlled trial," American Journal of Clinical Nutrition, vol. 83, no. 4, pp. 754$759,2006$. 


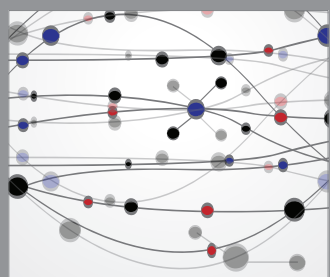

The Scientific World Journal
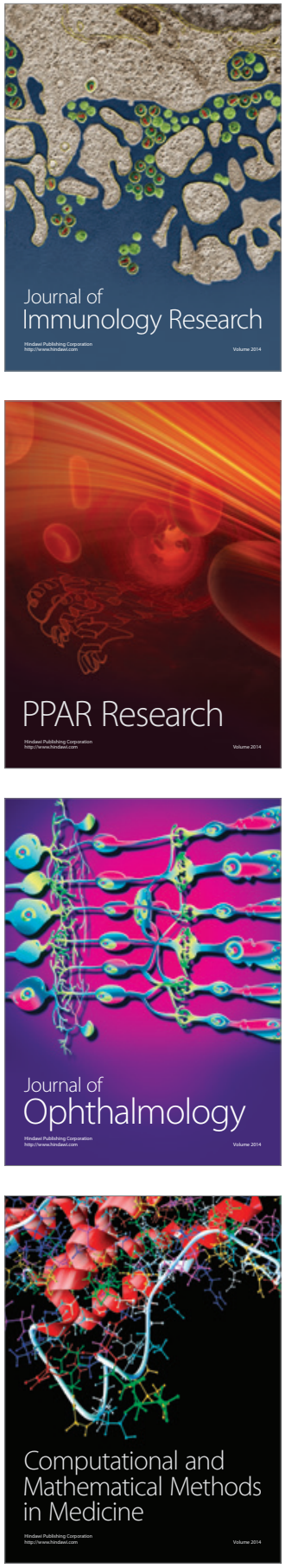

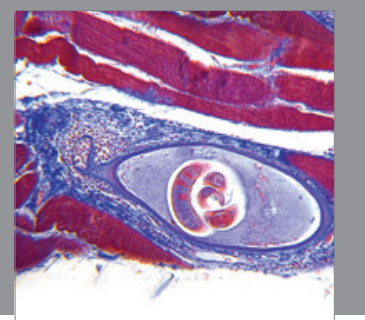

Gastroenterology

Research and Practice
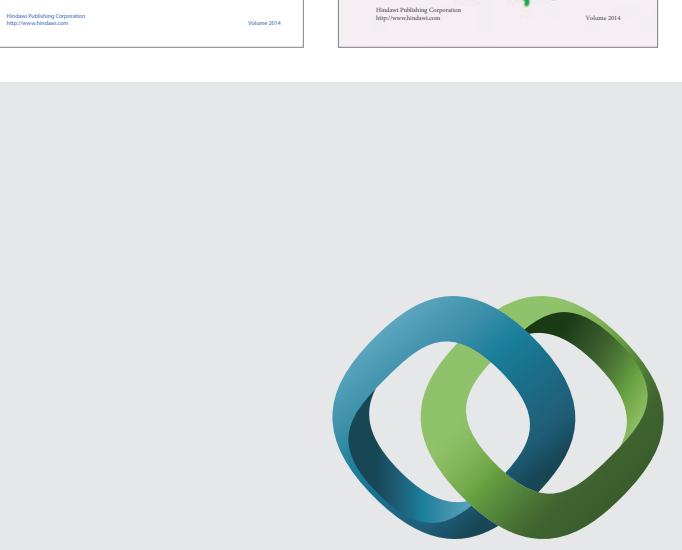

\section{Hindawi}

Submit your manuscripts at

http://www.hindawi.com
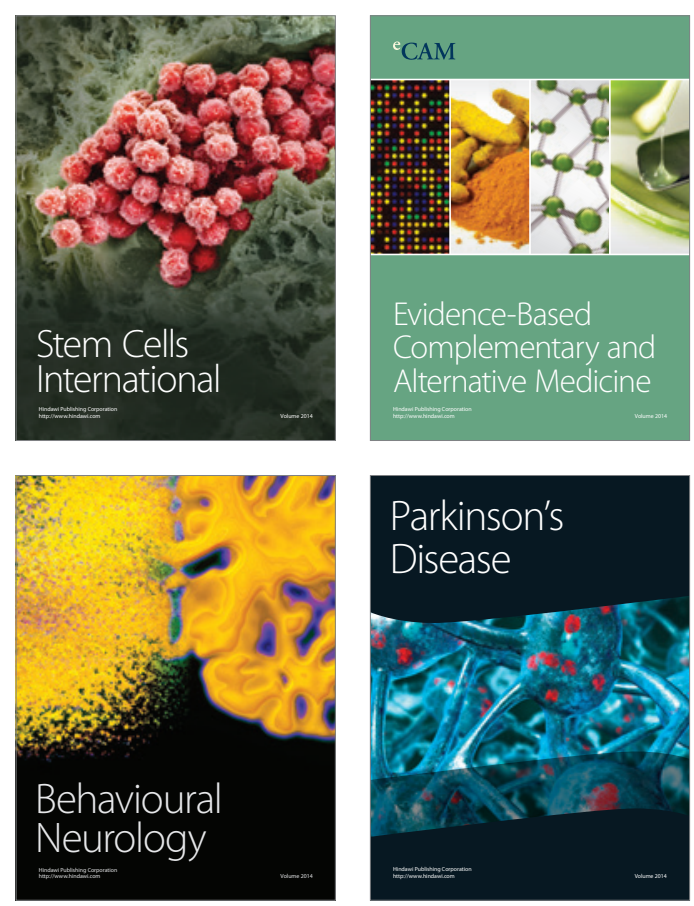

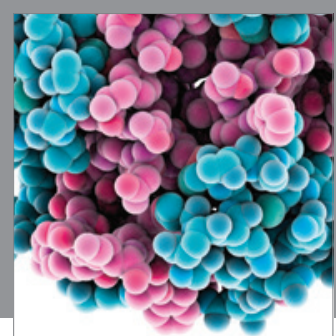

Journal of
Diabetes Research

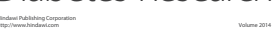

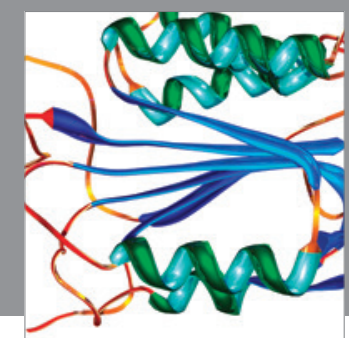

Disease Markers
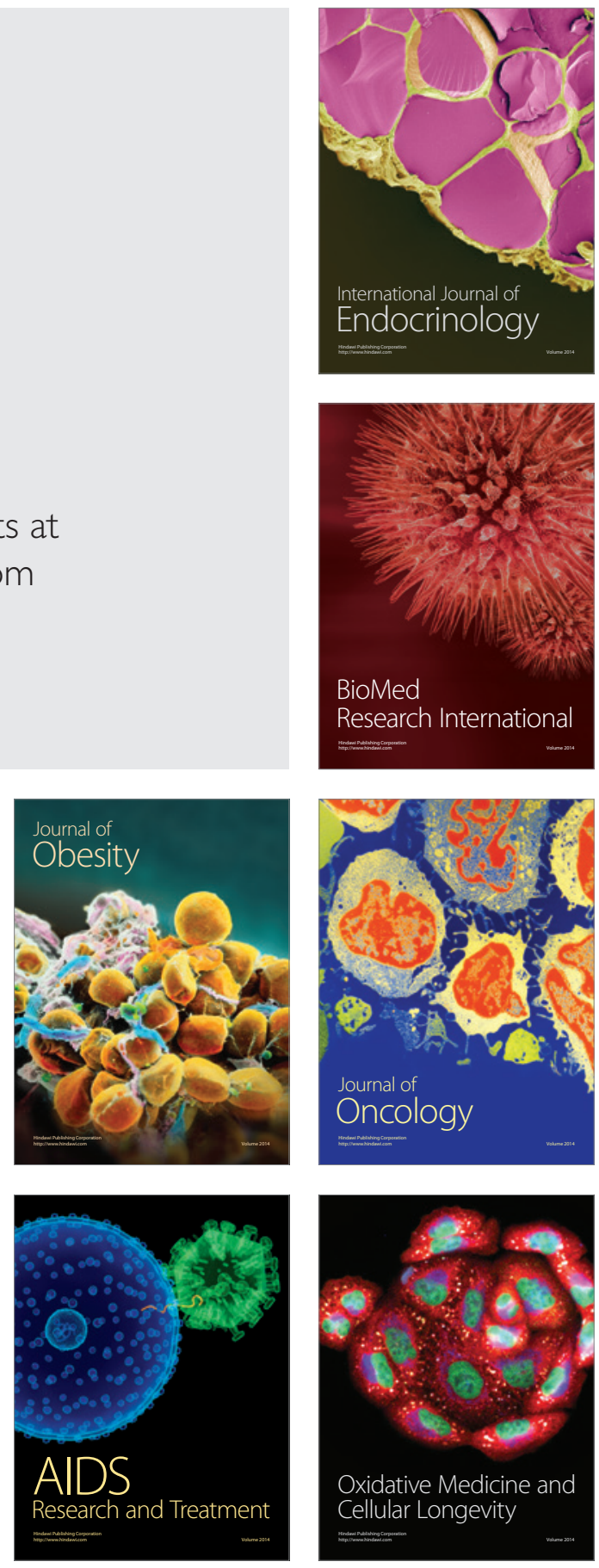